\title{
MÉXICo 2016: El DECLIVE DE LA CONFIANZA INSTITUCIONAL
}

\author{
Mexico 2016: The decline of Institutional trust
}

\section{FRANCISCO CANTÚ}

Universidad de Houston, USA

\section{VERÓNICA HOYO}

Universidad de California San Diego, USA

\section{RESUMEN}

El balance del 2016 para México es de saldo negativo: no solo las condiciones nacionales de violencia y descontento social siguieron empeorando sino que una coyuntura internacional particular — caracterizada por una situación económica volátil con el precio del petróleo y el valor del peso por los suelos y unas elecciones presidenciales norteamericanas que culminaron con Donald Trump como ganadorhicieron que el año registrara cifras sin precedentes de impopularidad presidencial, corrupción generalizada y falta de legitimidad en todos los niveles de gobierno y en la democracia misma.

Palabras clave: México, corrupción, violencia, incertidumbre económica

\begin{abstract}
Mexico finished 2016 in worse shape than it started: not only did national indicators worsen, mainly in terms of violence and social unrest, but the country also faced an increasingly hostile international climate characterized by a volatile economy with low oil prices, a depreciating peso, and the victory of Donald Trump in the US presidential elections. Consequently, the year ended with presidential approval ratings at an all-time low, widespread and unchecked corruption, and increasing concerns about the government's legitimacy and the future of democracy in Mexico.
\end{abstract}

Key words: Mexico, corruption, violence, economic uncertainty 


\section{INTRODUCCIÓN}

Si bien 2015 había ya sido un año complicado, la población mexicana no se imaginaba lo que le tenía esperado el 2016: no solo las condiciones nacionales de violencia y descontento social siguieron empeorando sino que una coyuntura internacional particular — caracterizada por una situación económica volátil con el precio del petróleo y el valor del peso por los suelos y unas elecciones presidenciales norteamericanas que culminaron con Donald Trump como ganador-, hicieron que el año registrara cifras sin precedentes de impopularidad presidencial y falta de legitimidad en todos los niveles de gobierno.

Los temas más sobresalientes del 2016 fueron, en resumen: la tercera recaptura de Joaquín "El Chapo" Guzmán, el repunte de los índices de inseguridad, la incesante corrupción de la clase política, el incontestable surgimiento de una crisis de refugiados en la frontera Norte del país y crecientes abusos de derechos humanos en la frontera Sur, la volatilidad económica y la incertidumbre en las relaciones con Estados Unidos de Norteamérica (EE.UU.). En conjunto, estos temas reflejan el desencanto de la sociedad civil y la total desconfianza en las instituciones políticas; el continuo deterioro del tejido social por la constante inseguridad y la incapacidad del, cada vez más débil, Estado mexicano para generar crecimiento económico y prosperidad equitativa. ${ }^{1}$

\section{COYUNTURA SOCIAL}

El año 2016 ha sido el año más violento en lo que va del sexenio de Enrique Peña Nieto, al registrarse un alza sostenida y significativa con respecto a 2015. La Tabla 1 muestra el número de carpetas de investigación abiertas por homicidio doloso durante 2016. En este plazo se contabilizaron 22.600 víctimas de homicidio; en comparación, el número total de 2015 que fue de 18.673 (Business Insider 2016, 23 de noviembre). Los estados más violentos fueron Chihuahua, Guerrero, Jalisco y el Estado de México, seguidos de cerca de Michoacán y Veracruz. ${ }^{2}$ Los recientes niveles de violencia no habían sido vistos desde 2011 (ver, por ejemplo, Olmeda y Armesto 2013) y siguen encontrando la misma fuente: peleas entre

\footnotetext{
De acuerdo con el Informe Latinobarómetro 2016 sobre el declive de la democracia, el 56\% de la población mexicana cree que la credibilidad política no se recuperará. Tan solo el 19\% de mexicanos cree que el país está progresando. Asimismo, el problema más importante del país en 2016 fue la delincuencia (30\%), seguido por problemas económicos (29\%) y por corrupción en tercer lugar (10\%). Estadísticas recuperadas de Corporación Latinobarómetro (2016).

2 Aunque existen diferentes métricas de violencia y el ranking de los Estados puede diferir en cada una de ellas, los mencionados en este texto aparecen siempre en los primeros lugares y la violencia en todos ellos está íntimamente ligada a las actividades del crimen organizado y sus luchas internas de poder. En particular, Chihuahua ha visto más violencia fronteriza (Ciudad Juárez) por la percepción de pérdida de poder del cartel de Sinaloa y el resurgimiento del cartel de Juárez. En Michoacán se trata de la ausencia de Estado de Derecho en lugares como Tierra Caliente y las peleas entre la Familia Michoacana, los Templarios, grupos de autodefensa y autoridades locales en el resto del territorio. Guerrero padece una situación parecida a la de Michoacán, entre Los Rojos y Guerreros Unidos e, incluso, lo que queda del cartel de Beltrán Leyva. En Jalisco se trata del cartel Nueva Generación. Los nombres cambian, el modus operandi y el impacto negativo en la sociedad civil es el mismo.
} 
grupos delictivos distintos y bandos de narcotraficantes por el control de los mercados. Ejemplos de estas peleas entre carteles a gran escala abundaron durante el año. ${ }^{3}$ Finalmente, y a pesar de que no hay duda sobre el incremento real y percibido de violencia, México tiene un importante problema de medición, particularmente en la precisión y confiabilidad de los datos estadísticos oficiales (IPE 2017). Un estudio reciente advierte que cualquier esfuerzo por detener el avance generalizado de la violencia que se vive en México se ve mermado por la falta de registros y bases de datos delictivos confiables (México Evalúa 2017).

No es entonces sorprendente que, de acuerdo con la Encuesta Nacional de Acceso a la Información Pública y Protección de Datos Personales, 45,5\% de la población de 18 años y mayores tiene mucha desconfianza en la información publicada por el gobierno en materia de seguridad pública, narcotráfico y delincuencia (INEGI 2016); tan solo 2,8\% expresó mucha confianza. Dado que los indicadores estadísticos son herramientas normalmente usadas en la evaluación del desempeño de los gobiernos federal, estatal y locales, dichos actores tienen fuertes incentivos para manipularlos y varios especialistas en violencia han encontrado inconsistencias y discrepancias significativas (David, Furszyfer y Gallegos 2017). Sin tasas de violencia y delincuencia verídicas, es imposible la identificación de políticas públicas a la medida del contexto particular de violencia que se pretenda reducir ("estrategias basadas en el lugar", IPE 2017) y también se dificulta la auténtica aplicación del marco legal y jurídico vigente en la investigación y resolución de actos delictivos. 
Tabla 1. Número de Investigaciones abiertas de asesinato por homicidio en México 2015-2016

\begin{tabular}{lrrr}
\hline \multicolumn{1}{c}{ Mes } & \multicolumn{3}{c}{2015} \\
& Homicidio doloso & Homicidio doloso & Cambio porcentual \\
\hline Enero & 1.289 & 1.427 & $+10,70$ \\
Febrero & 1.258 & 1.493 & $+18,68$ \\
Marzo & 1.315 & 1.542 & $+17,26$ \\
Abril & 1.379 & 1.533 & $+11,17$ \\
Mayo & 1.746 & 1.465 & $-16,09$ \\
Junio & 1.450 & 1.666 & $+14,89$ \\
Julio & 1.457 & 1.842 & $+26,42$ \\
Agosto & 1.564 & 1.938 & $+23,91$ \\
Septiembre & 1.481 & 1.974 & $+33,29$ \\
Octubre & 1.430 & 1.860 & $+30,07$ \\
Noviembre & 1.476 & 1.851 & $+25,41$ \\
Diciembre & 1.468 & 1.846 & $+25,75$ \\
Total & 17.313 & 20.437 & $+18,04$ \\
\hline
\end{tabular}

Fuente: Reportes mensuales sobre Delitos de Alto Impacto (enero, mayo-diciembre de 2016) del Observatorio Nacional Ciudadano recuperables en http:/ / onc.org.mx/tag/homicidio-doloso/

De manera relacionada, y a diez años del inicio de la guerra contra el narcotráfico y la delincuencia organizada, continúa el uso de fuerzas militares en operaciones de seguridad pública, las acusaciones de tortura, malos tratos, desapariciones forzadas, ejecuciones extrajudiciales, detenciones arbitrarias y violaciones de derechos humanos. En marzo, el Grupo Interdisciplinario de Expertos Independientes (GIEI) presentó su informe final sobre el caso de los 43 desaparecidos de Ayotzinapa. Dicho reporte determinó que la llamada "Verdad Histórica" que presentó la oficina del Procurador General no tenía fundamentos, específicamente, no hay evidencia de que los normalistas fueran a boicotear evento alguno o de que formasen parte del crimen organizado, entre otras faltas graves en la realización de la investigación por parte de las autoridades. El impacto negativo del caso de los " 43 " en la imagen del Estado mexicano, nacional e internacional, se sigue haciendo patente en cada función pública del Presidente mediante manifestaciones de protesta, pancartas e incluso en la constante presencia en medios de familiares de los desaparecidos y de organizaciones civiles aliadas con la causa.

En agosto, la Comisión Nacional de Derechos Humanos (CNDH) concluyó en un reporte que la policía federal fue responsable de violaciones graves de derechos humanos, en particular de la ejecución arbitraria de 22 civiles en una confrontación acaecida en mayo de 2015 en Tanhuato, Michoacán, cuyo saldo fue de 43 muertos (CNDH, 2016). Asimismo, hubo una manipulación de la escena del crimen y de las armas relacionadas con los cadáveres con el objeto 
de responsabilizar a los fallecidos y de encubrir las acciones de las fuerzas federales. A pesar de que el gobierno mexicano ha reconocido la existencia de al menos 27.000 desaparecidos y a que en 2015 se aprobó la reforma constitucional para darle facultades amplias en legislación del tema, el Congreso Federal sigue sin aprobar la Ley General de Desapariciones (Rebolledo 2017).

Si bien es cierto que, para los mexicanos, la violencia más dañina para el país se trata del crimen organizado $(73 \%)$, también resulta importante notar el estado de otros tipos de violencia (Corporación Latinobarómetro 2016). Tal es el caso, primero, de la violencia de género. Creada en 2007 , la alerta de violencia de género es un mecanismo de protección de los derechos humanos de las mujeres, establecido en la ley mexicana con el objeto de enfrentar y erradicar la violencia femicida. ${ }^{4}$ En 2016 se duplicaron dichas alertas al establecerse las correspondientes en los estados de Michoacán, Chiapas, Nuevo León y Veracruz. De manera relacionada, en septiembre, la Comisión Interamericana de Derechos Humanos remitió a la Corte Interamericana de Derechos Humanos (Corte IDH) el caso de once mujeres de San Salvador Atenco sometidas a violencia sexual como tortura. Ni la alerta de género ni los recursos gubernamentales destinados a la "atención y prevención" de este particular tipo de violencia han servido para evitar su recrudecimiento (Casanova 2017).

En segundo lugar, en términos de libertad de prensa y su protección, México se caracteriza por ser uno de los países más letales para los periodistas. El último reporte anual de Reporteros Sin Fronteras clasifica a nuestro país en el lugar 149 de un total de 182 países evaluados en su índice de libertad de prensa, por debajo de Honduras, Filipinas, Venezuela, Sudán, Pakistán y Rusia. Asimismo, dicha organización enfatizó el carácter depredador del cartel de "los Zetas" - originalmente, un grupo paramilitar surgido como comando de ajuste de cuentas (ver Palma 2010) — frente a la prensa y la completa impunidad en la que opera en los estados del noreste del Golfo de México. Dicho reporte cuantificó en trece el número de profesionales de la información asesinados (Reporteros Sin Fronteras 2016), número que se sigue incrementando con el tiempo. Asimismo, la Fiscalía Especial para la Atención de Delitos Cometidos contra la Libertad de Expresión (FEADLE) reveló que en los últimos seis años se han abierto 798 averiguaciones previas por delitos contra periodistas (FEADLE 2016).

En este contexto de creciente violencia, ausencia de Estado de Derecho y negligencia de las autoridades, no parece sorprendente que México ocupe el segundo lugar de mayor victimización de delitos en Latinoamérica, 46\%, tan solo por detrás de Venezuela (48\%) (Corporación Latinobarómetro 2016), ni que los ciudadanos cuestionen la capacidad del gobierno mexicano de cumplir su más básica función, en tanto garante de seguridad.

4 Aunque fue hasta 2015 que se declararon oficialmente los dos primeros casos (EdoMex y Morelos). A la fecha continúan 13 solicitudes pendientes de aprobación (Instituto Nacional de las Mujeres 2017). 


\section{COYUNTURA ECONÓMICA}

En contra de la norma observada en Latinoamérica, la economía mexicana en los últimos veinte años ha sobresalido por su disciplina macroeconómica. Los primeros meses de 2016 siguieron la misma tendencia y mostraron la resiliencia del país ante la caída en los precios petroleros. Sin embargo, la aclamada estabilidad económica mostró límites preocupantes ante los efectos de la elección presidencial norteamericana y la decisión de cambiar el esquema de precios para la venta de la gasolina que entró en vigor el primero de enero de 2017.

El 2016 confirmó también los riesgos que traen la dependencia del presupuesto público en la producción petrolera. La caída de los precios del petróleo por segundo año consecutivo y la baja producción de Petróleos Mexicanos, la empresa paraestatal que gozaba hasta el año pasado de la exclusividad en la exploración, extracción y venta del petróleo en el país, mermó las arcas públicas de manera considerable. A pesar de que el declive de la producción petrolera ha sido un problema del país en los últimos años (ver, por ejemplo, Langston y Pérez 2009), su efecto se ha recrudecido en los ingresos del gobierno. Mientras que los ingresos petroleros representaron $45 \%$ de los ingresos públicos totales en 2008, este rubro significó solo el 18\% en 2016, lo que desajustó de manera significativa los planes de gasto público del gobierno federal (Albarrán 2016). En palabras del presidente Peña Nieto, los ajustes en los ingresos públicos a consecuencia de la pobre producción petrolera en 2016 dejan en claro que "se acabó la gallina de los huevos de oro" para el gobierno federal (El Economista 2017, 12 de enero).

Una consecuencia de esta caída fue el creciente déficit público que, si bien aún se mantiene en márgenes manejables (2,6\% del PIB), está en niveles por arriba de los registrados en los últimos 25 años. Sin embargo, la estabilidad en la inflación registrada durante el año mostró el papel toral del Banco Central mexicano. Su decisión de subir las tasas de interés produjo certidumbre financiera y ha ayudado a tener presiones inflacionarias a flote durante la primera mitad de 2016.

Para contrarrestar la baja en la producción del petróleo, el gobierno continuó la adjudicación de campos petroleros para la exploración del sector privado. Estas subastas son el resultado de la reforma energética promulgada en 2013 (Barrientos del Monte y Añorve 2014) y un precedente histórico desde la iniciación de la explotación petrolera en 1938. Los primeros resultados, sin embargo, estuvieron lejos de lo planeado. De las catorce áreas de aguas someras que se subastaron para exploración en 2015, el gobierno adjudicó únicamente dos. Para 2016, el gobierno aprendió la lección y modificó las reglas de adjudicación, pudiendo colocar ocho de los diez campos subastados, cuatro de ellos otorgados a extranjeros asociados para la explotación con empresas mexicanas. 
Pero la nota más crítica de la economía mexicana en 2016 fue la extraordinaria depreciación del tipo cambiario, lo que convirtió al peso mexicano en la moneda que más perdió su valor frente al dólar durante el año. Entre las razones de la devaluación se incluyen la caída de los precios y la producción del petróleo, el bajo crecimiento de las exportaciones no petroleras, y la incertidumbre internacional en los mercados a consecuencia del resultado del Brexit y las alzas de las tasas de interés por parte de la Reserva Federal Americana (Espinoza 2015).

Gráfico 1. Tipo de cambio

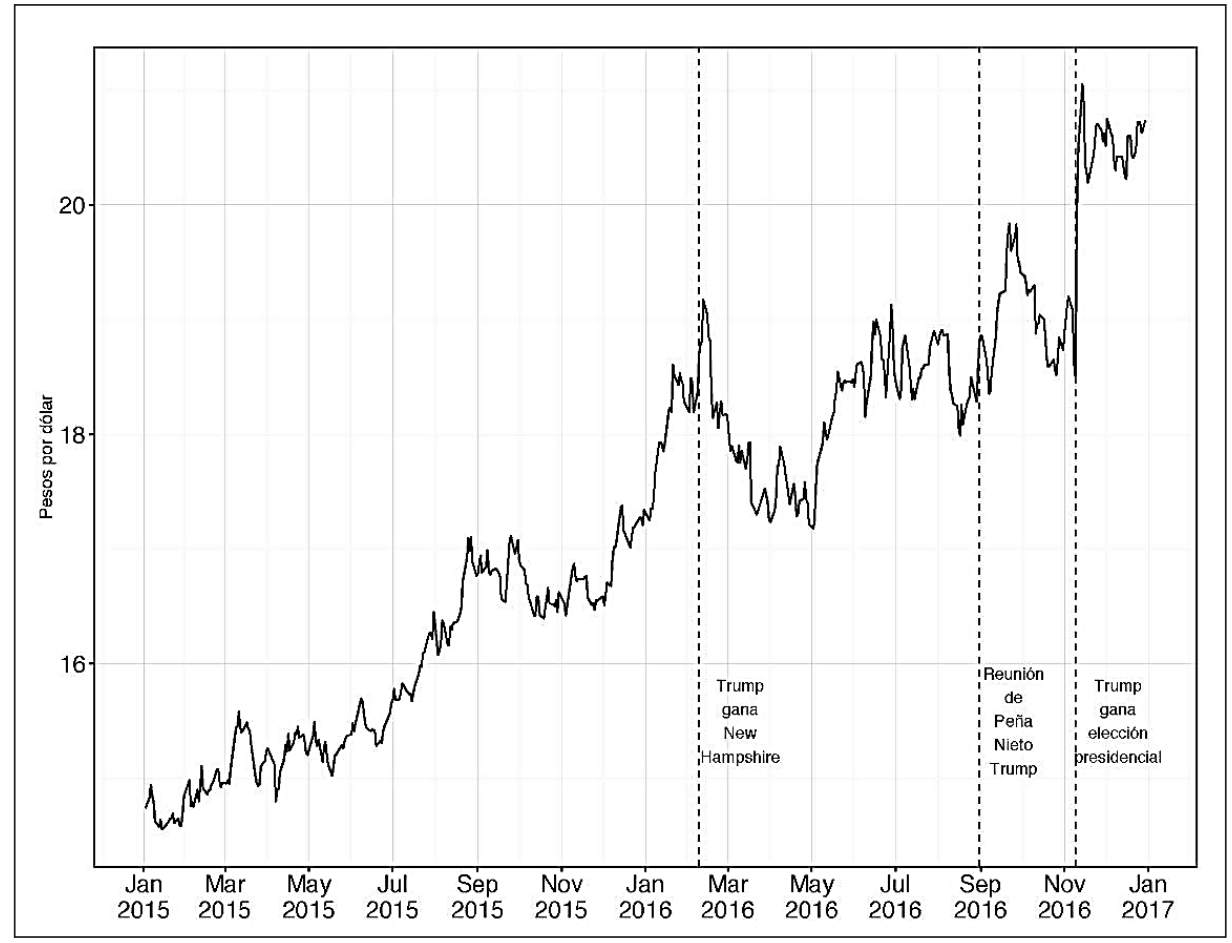

Fuente: Banco de México http:/ / www.banxico.org.mx/portal-mercado-cambiario/

La economía mexicana dejó claro que su talón de Aquiles es su dependencia extrema de su principal socio comercial: Estados Unidos. Las políticas proteccionistas anunciadas por Donald Trump, y su paso para convertirse en un serio contendiente por la presidencia, convirtieron a la moneda mexicana en un activo de protección ante el eventual triunfo del magnate. Al mismo tiempo, las amenazas del candidato republicano para suspender en Tratado de Libre Comercio de América del Norte y el supuesto reembolso por parte del gobierno mexicano de la construcción de un nuevo y mejorado muro fronterizo entre los dos países crearon incertidumbre en los mercados, logrando que el flujo del peso se mimetizara con las expectativas de los inversionistas sobre el triunfo electoral de Trump. El gobierno trató de disminuir la incertidumbre en los 
mercados a finales de agosto, cuando invitó al candidato a la Ciudad de México. Sin embargo, la visita no cambió la posición de Trump ni obtuvo los resultados esperados (ver sección de coyuntura internacional más adelante).

En consecuencia, la caída del peso se agravó ante la victoria del candidato republicano. Como el Gráfico 1 lo demuestra, el peso mexicano se devaluó 16\% entre el 1 de enero y el 31 de diciembre del 2016, y se depreció 11\% si se considera su valor el día anterior a la elección americana. Este fenómeno abre una importante agenda de investigación para estudiar las consecuencias económicas de las campañas políticas y las elecciones tanto locales (Benton y Smith 2017) como internacionales.

Otra consecuencia de la victoria de Donald Trump en la economía mexicana fue el incremento en las remesas provenientes de la Unión Americana, llegando a la cifra histórica de 26 mil millones de dólares. Este monto representa casi tres por ciento del producto interno bruto (PIB) en el país y un incremento de casi 9\% respecto de 2015 (Lozano y González 2017). Los analistas explican esta alza como una anticipación de los connacionales que radican en Estados Unidos a las posibles deportaciones durante la administración de Trump. Solamente durante el mes de la elección americana, noviembre de 2016, las remesas reportadas fueron de 2.400 millones de dólares, lo que significó un incremento de $25 \%$ respecto a lo registrado en noviembre del año anterior (The Economist, 2017).

Aunque este año no se registró ningún cambio mayor, la desigualdad en la distribución del ingreso disponible, medido por el coeficiente de Gini, continúa situando a México en los últimos lugares de los 35 países que conforman la OCDE (Organización para la Cooperación y el Desarrollo Económico), acompañado tan solo por Turquía y Chile (OCDE 2016).

\section{COYUNTURA SUBREGIONAL E INTERNACIONAL}

En materia internacional, 2016 fue el año en el que el gobierno mexicano echó por la borda cualquier reputación de adherencia a los principios de no intervención en la política interna de otros países. En una insólita decisión y aconsejado por el entonces Secretario de Hacienda, actual Canciller, Luis Videgaray, el presidente Peña Nieto invitó al candidato republicano Donald Trump a Los Pinos en plena campaña presidencial (31 de agosto de 2016). No obstante, Donald Trump aprovechó la conferencia de prensa conjunta para mostrarse presidenciable y en control, aunque de vuelta a EE.UU. retomó el tono agresivo y las amenazas de que México pagaría el nuevo muro, enfatizando que Peña Nieto estaba al tanto del tema. Inmediatamente tras la visita, las críticas y el rechazo al gobierno no se hicieron esperar. En una encuesta realizada por El Universal (Aleé 2016), $88 \%$ de los entrevistados consideró "una mala decisión" la invitación y siete de cada diez mexicanos se sintieron ofendidos por la misma. La clase política, los académicos y la sociedad civil mexicana se unieron en la indignación frente a lo que fue descrito como una postura de sometimiento y humillación ante el 
vecino del Norte que culminó con la renuncia del autor intelectual de la visita, Luis Videgaray.

Este año, México recibió el mayor número de peticiones de asilo en la historia, la gran mayoría $(91,6 \%)$ provenientes de personas centroamericanas (El Salvador, Honduras y Guatemala, en particular) huyendo de la violencia de sus países de origen. De acuerdo con cifras de la Agencia de la ONU para los Refugiados (ACNUR 2017), durante 2016, 8.781 personas solicitaron protección como refugiadas, un incremento de $1067 \%$ en comparación con las solicitudes recibidas en 2011 (ver Gráfico 2).

Gráfico 2. Número de solicitudes de asilo y de otorgamiento de condición de refugiados por año (2006-2016)

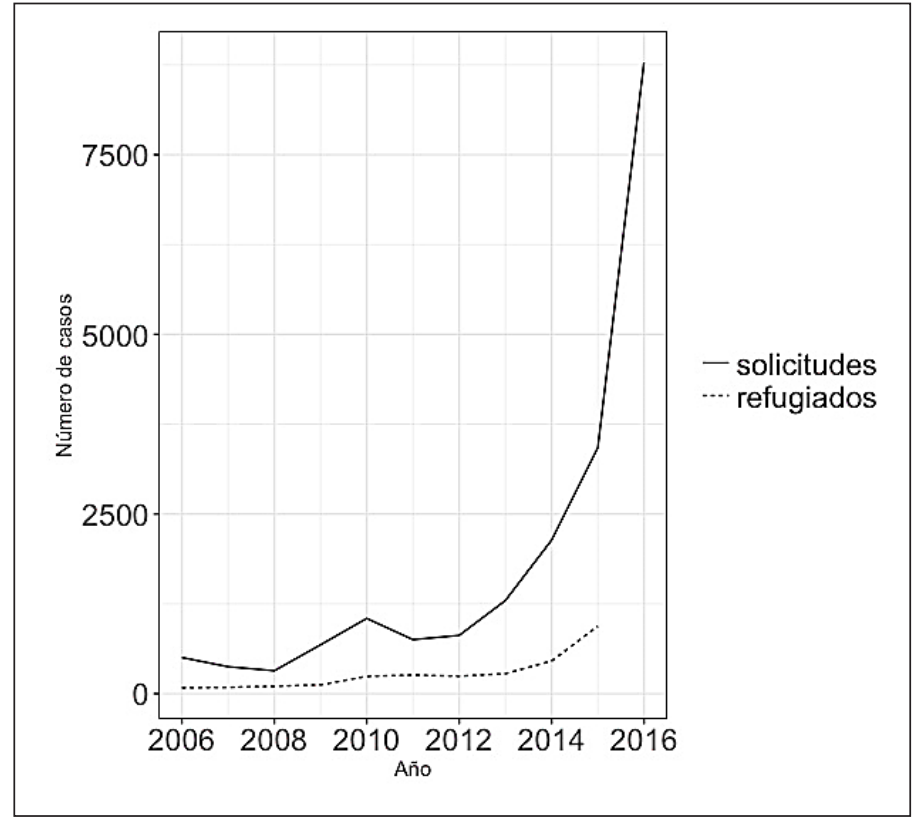

Fuente: ACNUR, COMAR en Hernández (2017, 10 de febrero)

Asimismo, a principios de octubre y debido a las restricciones en EE.UU. para darles asilo, más de 5.000 personas provenientes de Haití, Cuba y África quedaron varadas en Tijuana y Mexicali, eventualmente ocasionando una emergencia migratoria que obligó al Secretario de Gobernación, Miguel Ángel Osorio Chong, a manifestarse sobre el asunto y anunciar el destino de recursos federales para atender "una situación extraordinaria" que el gobierno oficialmente se negó a tratar de crisis humanitaria, al menos inicialmente, en sus discursos (Heras 2016). 
En términos de la frontera Sur, y a dos años del inicio del "Programa Frontera Sur" (PIFS) como medida de colaboración con EE.UU. y para controlar el flujo migratorio centroamericano a ese país, se ha dado un incremento en las operaciones de seguridad en nuestras fronteras con Guatemala y Belice. Dichas operaciones han dado lugar a frecuentes acusaciones de extorsión, expulsiones masivas, secuestros y otros abusos de derechos de los migrantes. Hasta noviembre de 2016, 174.526 migrantes irregulares fueron capturados y detenidos, mientras que 136.420 de ellos fueron deportados a sus países de origen (Amnistía Internacional 2017). Para dichas labores y a través de la llamada "Iniciativa Mérida" (ver Magar y Romero 2008), EE.UU. entregó recursos por 161 millones de dólares como aportación para paz, seguridad, democracia, derechos humanos y gobernanza. Sin embargo, el costo humano de estas operaciones ha sido prácticamente ignorado por ambos gobiernos. De acuerdo con la CNDH, hasta mayo se habían contabilizado al menos 35.433 víctimas de desplazamiento interno, de las cuales los más afectados por las precarias condiciones de vida en los centros de detención de migrantes fueron niños y niñas no acompañados. Se especula que la llegada de Donald Trump a la Casa Blanca pondrá al menos un alto, sino es que el fin, a toda colaboración transfronteriza.

\section{COYUNTURA POLÍTICA}

A inicios de año, el 8 de enero, tras una singular fuga del penal de máxima seguridad del Altiplano (ver Freidenberg y Aparicio 2016) y tras cinco meses de evadir captura, el líder del cartel de Sinaloa, el narcotraficante Joaquín Guzmán Loera, "el Chapo", fue aprehendido por tercera vez. Se trató de un operativo llevado a cabo por elementos de la Marina y de la Policía Federal en Los Mochis, Sinaloa, en una casa de seguridad donde no se esperaba que estuviera el capo. A pesar de lo fortuito, el operativo fue exitoso y terminó con su captura y un saldo de cinco muertos (todos ellos "agresores"), seis detenidos y un militar lesionado. Un día después de que Peña Nieto anunciara la noticia de su recaptura en su cuenta de Twitter como una "misión cumplida", la revista Rolling Stone publicó en su portal en línea un reportaje exclusivo con el Chapo realizado meses antes, mientras aún era un fugitivo y supuestamente inalcanzable. ${ }^{5}$ Dicho reportaje opacó los festejos oficiales de la reaprehensión y, en buena medida, presionó al gobierno para acelerar los procedimientos de extradición de Guzmán a EE.UU., donde enfrenta acusaciones de narcotráfico en al menos doce Estados. Pero sobre todo demostró una vez más la ineficacia del Estado mexicano para cumplir no solo sus funciones básicas sino también su inhabilidad para diseñar una política de comunicación social coherente que pudiera favorecer su imagen frente a la ciudadanía (Fox News 2016, 4 de febrero).

El texto completo del twitter presidencial decía: “Misión cumplida: lo tenemos. Quiero informar a los mexicanos que Joaquín Guzmán Loaera ha sido detenido" 10:19 am- 8 de junio de 2016 @EPN. 
Los escándalos de corrupción siguen acechando al gobierno mexicano en todos los niveles. Durante este año, varios exgobernadores estuvieron en los reflectores por acusaciones graves o averiguaciones previas de malversación de fondos públicos, uso de prestanombres, lavado de dinero y delincuencia organizada (ver Tabla 2). La corrupción en México no es novedad, por algo es el país más corrupto de los treinta y cinco miembros de la OCDE al ocupar el lugar 123 del índice de percepción de corrupción de Transparencia Internacional, empatado con Azerbaijan, Djibouti, Honduras, Laos, Moldova, Paraguay y Sierra Leona (Transparency International 2017). ${ }^{6}$ Lo verdaderamente notable este año en este rubro fue la amplia cobertura mediática del innegable contubernio del partido en el poder (el PRI) con sus operadores políticos a nivel estatal y local, lo cual permitió a estos últimos desfalcar las arcas a su antojo mientras las autoridades hacían la vista gorda. Antes de la llegada del "nuevo PRI" de Peña Nieto, los gobernadores que se volvían "incómodos" eran despachados somera y discretamente con el objeto de evitar que su mala reputación pudiese manchar la del Ejecutivo (García 2017). Incluso durante su campaña presidencial, el entonces candidato Peña Nieto citaba como ejemplo de renovación de su partido a tres de los cinco nombres de exgobernadores acusados de corrupción (ver Tabla 2) (Aristegui Noticias 2016, 5 de agosto). Quizá la única diferencia entre el PRI de antaño y el renovado es la comodidad de sus agentes para violar la ley sin temor a ninguna represalia legal o, siquiera, presidencial. Javier Duarte, exgobernador de Veracruz, no se inmutó en su actuar durante cinco años de gobierno priísta ni fue siquiera objeto de interés de la Procuraduría, también príista, sino hasta después de un reportaje periodístico detallando sus robos (Puig 2017). Los únicos cambios notables parecieran ser la pérdida de poder del Ejecutivo frente a los gobernadores, la timorata respuesta de la estructura partidaria del PRI ante la corrupción (expulsión extemporánea y puramente simbólica de sus filas) y la creciente importancia de los medios de información en las labores de rendición de cuentas.

6 El registro de 2016 fue de 30,5 puntos más bajo que el valor inmediato anterior (2015) y el peor de los últimos cinco años. El índice se mide en una escala de 0 a 100, donde 0 significa altos niveles de corrupción y 100 que son bajos niveles de corrupción. 
Tabla 2. Los exgobernadores corruptos

\begin{tabular}{|c|c|c|c|c|}
\hline Nombre & Cargo público & $\begin{array}{l}\text { Partido } \\
\text { político }\end{array}$ & Acusación & Resolución \\
\hline $\begin{array}{l}\text { Humberto } \\
\text { Moreira }\end{array}$ & $\begin{array}{l}\text { Gobernador } \\
\text { de Coahuila } \\
\text { (2005-2011) } \\
\text { Presidente } \\
\text { Nacional de su } \\
\text { partido (2011) }\end{array}$ & PRI & $\begin{array}{l}\text { Malversación de fondos } \\
\text { públicos y lavado de dinero }\end{array}$ & $\begin{array}{l}\text { Arrestado en España } \\
15 / 01 / 2016 ; \text { libre bajo } \\
\text { fianza y esperando } \\
\text { juicio }\end{array}$ \\
\hline $\begin{array}{l}\text { Javier } \\
\text { Duarte }\end{array}$ & $\begin{array}{l}\text { Gobernador de } \\
\text { Veracruz (2010- } \\
\text { 2016) }\end{array}$ & PRI & $\begin{array}{l}\text { Acusado de la quiebra de su } \\
\text { Estado por montos de } 182 \\
\text { mil } 895 \text { millones de pesos en } \\
\text { deudas, desvíos y pasivos } \\
\text { acumulados } \\
\text { Lavado de dinero en } \\
\text { propiedades y transferencias } \\
\text { bancarias internacionales } \\
\text { millonarias }\end{array}$ & Prófugo \\
\hline $\begin{array}{l}\text { César } \\
\text { Duarte }\end{array}$ & $\begin{array}{l}\text { Gobernador } \\
\text { de Chihuahua } \\
(2010-2016)\end{array}$ & PRI & $\begin{array}{l}\text { Peculado y enriquecimiento } \\
\text { ilícito. Déficit estatal de más } \\
\text { de } 7 \text { mil } 207 \text { millones de } \\
\text { pesos; adquisición personal } \\
\text { de acciones del Banco } \\
\text { Progreso de Chihuahua por } \\
\text { un monto de } 65 \text { millones de } \\
\text { pesos }\end{array}$ & $\begin{array}{l}\text { Libre y amparado } \\
(24 / 02 / 2017)\end{array}$ \\
\hline $\begin{array}{l}\text { Guillermo } \\
\text { Padrés }\end{array}$ & $\begin{array}{l}\text { Gobernador de } \\
\text { Sonora (2009- } \\
2015)\end{array}$ & PAN & $\begin{array}{l}\text { Defraudación fiscal, } \\
\text { delincuencia organizada } \\
\text { ( } 312 \text { millones de pesos de } \\
\text { procedencia ilícita de los } \\
\text { cuales } 178 \text { eran del erario } \\
\text { estatal) y lavado de dinero } \\
\text { por } 8,8 \text { millones de dólares a } \\
\text { través de la empresa Minera } \\
\text { SWF, de su propiedad. }\end{array}$ & En prisión \\
\hline $\begin{array}{l}\text { Roberto } \\
\text { Borge }\end{array}$ & $\begin{array}{l}\text { Gobernador de } \\
\text { Quintana Roo } \\
(2011-2016)\end{array}$ & PRI & $\begin{array}{l}\text { Delincuencia organizada. } \\
\text { Desvío de } 25 \text { mil millones } \\
\text { de pesos, viajes millonarios } \\
\text { al extranjero }\end{array}$ & Libre \\
\hline $\begin{array}{l}\text { Miguel } \\
\text { Alonso } \\
\text { Reyes }\end{array}$ & $\begin{array}{l}\text { Gobernador de } \\
\text { Zacatecas } \\
\text { Actual Director } \\
\text { del Fonatur ( } 29 \\
\text { nov 2016-) }\end{array}$ & PRI & $\begin{array}{l}\text { Desvío de recursos públicos } \\
\text { (307,4 millones de pesos) }\end{array}$ & $\begin{array}{l}\text { Libre. } \\
\text { Denuncia presentada } \\
\text { por MORENA ante } \\
\text { PGR }\end{array}$ \\
\hline
\end{tabular}

Fuente: elaboración propia

En un episodio casi de realismo mágico, en abril, el Instituto Nacional Electoral (INE) interpuso una denuncia contra quien resulte responsable de haber subido a internet la base de datos del listado nominal de electores con fecha de corte 15 de febrero de 2015. Dicho archivo contenía nombres y domicilios del padrón de 87,4 millones de ciudadanos (Chávez 2016). Tras la denuncia, la dirigencia 
de Movimiento Ciudadano reconoció a través de su líder, Dante Delgado, haber sido responsables de subir la información a la nube. Meses antes, el INE había sancionado (con 76 millones de pesos) a Movimiento Ciudadano por "negligencia en el manejo del padrón electoral". Como respuesta a lo sucedido, en diciembre, el INE celebró una sesión extraordinaria para discutir medidas de reforzamiento de seguridad y protección de datos (INE 2016).

\section{CAMBIOS INSTITUCIONALES: ELECCIONES LOCALES}

El 5 de junio se eligieron doce gobernadores, 547 ayuntamientos y 422 asientos a congresos locales. La organización de estas elecciones siguió el esquema de la reforma electoral de 2013, la cual provee al Instituto Nacional Electoral de un rol central en la fiscalización de recursos en las campañas y la utilización de la misma reglamentación electoral para todos los estados (Freidenberg y Aparicio 2016).

Las campañas electorales estuvieron marcadas por una sobreexposición mediática de los candidatos, excesivos gastos de campaña y amenazas de violencia durante la jornada electoral. La mayor amenaza a las elecciones vino por parte de la Coordinadora Nacional de los Trabajadores de la Educación (CNTE), quienes usaron el amedrentamiento de impedir la apertura de casillas electorales como medida de presión para frenar la implementación de la reforma educativa. Otros eventos de violencia pre-electoral fueron promovidas por grupos no identificados, como los que atacaron la sede del Partido Revolucionario Institucional (PRI) en Jalapa, Veracruz, y el ataque a las casas de campaña de los candidatos del PRI y del PAN en Ahome, Sinaloa (El Universal 2016, 5 de junio). Las advertencias de una potencial jornada violenta y la falta de campañas informativas produjeron una de las elecciones con menor participación electoral en el país, ya que solamente el 32\% de los votantes registrados para participar en las elecciones locales acudió a las urnas.

La noticia más destacada de la jornada electoral fue la derrota de los candidatos del Partido Revolucionario Institucional (PRI) en siete de las doce contiendas para gobernador. A pesar recuperar dos Estados que había perdido seis años antes (Sinaloa y Oaxaca), el PRI sufrió derrotas, por primera vez en su historia, en los Estados de Veracruz y Tamaulipas. El balance negativo para el PRI se acentúa si se compara su desempeño en las elecciones locales en las mismas entidades seis años atrás, en las cuales el partido sufrió derrotas en solo tres de las doce contiendas para gobernador (Temkin Yewad y Salazar-Elena 2011). Por su parte, el PAN obtuvo seis triunfos, dos de los cuales fueron obtenidos por candidatos postulados por una coalición con el Partido de la Revolución Democrática (PRD). Esta combinación de resultados produjo el menor número de Estados en manos del PRI desde su creación, dejando a los partidos de oposición con el control del Ejecutivo estatal en 16 de las 32 entidades federativas. 
Existen dos hipótesis potenciales para explicar los resultados en estas elecciones locales. La primera sugiere que los pobres resultados para el PRI responden a la impopularidad del partido y el presidente en el país. La incapacidad para reducir el crimen, el bajo crecimiento económico, así como los escándalos de corrupción del gobierno federal han mermado la aprobación presidencial y la identificación partidista con el PRI. Además, la desacreditación del Presidente fue aprovechada efectivamente por el PAN, quien canalizó la movilización electoral de grupos católicos y evangélicos que se opusieron a las propuestas del gobierno federal para permitir el matrimonio homosexual y la legalización de la marihuana (Beauregard 2016).

Una segunda hipótesis sugiere que la reacción del electorado fue más responsiva a nivel local, y que las derrotas electorales del PRI son consecuencia de los escándalos que involucraron a varios gobernadores previo a las elecciones locales (ver Tabla 2). Destacan las acusaciones de corrupción de los gobernadores de Veracruz, Chihuahua y Oaxaca, quienes enfrentaron las elecciones locales con cifras de aprobación inferiores al 30\% (Consulta Mitoksky 2017). En resumen, los resultados fueron consecuencia del desprestigio de los mandatarios locales.

Más allá de las contiendas para gobernador, la elección local con mayor atención mediática fue la llevada a cabo en la Ciudad de México, donde los ciudadanos eligieron a los miembros de la asamblea que discutiría y aprobaría su nueva constitución local. Además de la excepcionalidad de la contienda, la elección en la capital del país sirvió como laboratorio para explorar la fuerza y fragmentación de la izquierda en uno de sus bastiones históricos. El recién creado MORENA se llevó la mayoría relativa de la elección con 36\% de los votos, seguido del PRD con $32 \%$. Los resultados sugieren que la izquierda capitalina obtuvo más del $70 \%$ de los votos, pero su división en varios partidos inhabilita su potencial.

Un común denominador en la mayoría de las elecciones fueron las declaraciones anticipadas de victoria de la mayoría de los candidatos y la descalificación de los resultados electorales al momento de ser anunciados. A pesar de que la mayoría de las acusaciones no tuvieron los fundamentos para ser defendidas ante el tribunal electoral, destacan irregularidades esporádicas, incluyendo la detención de 130 personas por delitos electorales.

La elección dejó distintos balances para los partidos. En primer lugar, el PAN se posicionó como uno de los principales contendientes para disputar la silla presidencial en la elección de 2018. Las encuestas seguidas de la elección local situaban a este partido como el líder de las preferencias partidistas para 2018, situación que ocurría por primera vez en siete años (Parametría 2016a). Al mismo tiempo, las victorias del partido posicionaron a su líder, Ricardo Anaya, como un posible candidato para la carrera presidencial. El PRD volvió a ser víctima de la fragmentación de la izquierda mexicana. El partido no pudo ganar una sola elección por sí mismo y sus triunfos fueron producto de su coalición con el PAN para evitar tanto las victorias del PRI como las de su antiguo líder, Andrés Manuel López Obrador. La presión para evitar coaliciones y las 
presiones internas provocaron la renuncia de su presidente Agustín Basave, a solo siete meses de asumir el cargo. Andrés Manuel López Obrador, junto a su Movimiento de Regeneración Nacional, dejó ver que su fuerza electoral, aunque importante y en crecimiento, no se tradujo en poder real. MORENA logró posicionarse en algunos Estados, obteniendo proporciones de voto cercanas al $25 \%$ en Oaxaca, Zacatecas y Veracruz. Estos números se quedaron cortos para obtener la victoria, demostrando que su apoyo electoral está focalizado en áreas específicas del país.

Por último, el PRI tuvo una grave crisis tanto por las limitaciones de su movilización electoral, por el desprestigio de sus candidatos y gobernadores salientes, así como por su baja aprobación de cara a las elecciones presidenciales. Esta situación forzó la renuncia de su presidente, Manlio Fabio Beltrones, en sustitución de Enrique Ochoa-Reza, y en la destitución de sus derechos partidistas a varios exgobernadores priístas envueltos en escándalos de corrupción.

Tabla 3. Resultados de elecciones para Gobernador

\begin{tabular}{|c|c|c|c|c|}
\hline Entidad & $\begin{array}{l}\text { Candidato } \\
\text { ganador }\end{array}$ & $\begin{array}{l}\text { Partido coalición } \\
\text { ganadora }\end{array}$ & $\begin{array}{l}\text { Porcentaje de } \\
\text { votación }\end{array}$ & $\begin{array}{l}\text { Partido del } \\
\text { gobernador } \\
\text { saliente }\end{array}$ \\
\hline Aguascalientes & Martín Orozco & PAN & $43,51 \%$ & PRI-PVEM \\
\hline Chihuahua & Javier Corral & PAN & $39,51 \%$ & $\begin{array}{l}\text { PRI-PVEM-NA- } \\
\text { PT }\end{array}$ \\
\hline Durango & $\begin{array}{l}\text { José Rosas- } \\
\text { Aispuro }\end{array}$ & PAN-PRD & $46 \%$ & PRI \\
\hline Hidalgo & Omar Fayad & PRI-PVEM & $43,6 \%$ & PRI-PVEM-NA \\
\hline Oaxaca & Alejandro Murat & PRI-PVEM-NA & $32 \%$ & PAN-PRD-PT-PC \\
\hline Puebla & Antonio Gali & $\begin{array}{l}\text { PAN-PT-NA- } \\
\text { CP-PSI }\end{array}$ & $45,4 \%$ & $\begin{array}{l}\text { PAN-PRD-PC- } \\
\text { NA }\end{array}$ \\
\hline Quintana Roo & $\begin{array}{l}\text { Carlos Manuel } \\
\text { Joaquín } \\
\text { González }\end{array}$ & PAN-PRD & $45,7 \%$ & $\begin{array}{l}\text { PRI-PVEM- } \\
\text { PANAL }\end{array}$ \\
\hline Sinaloa & Quirino Ordaz & PRI-PVEM-NA & $41,2 \%$ & PAN-PRD-PC \\
\hline Tamaulipas & $\begin{array}{l}\text { Francisco García } \\
\text { Cabeza de Vaca }\end{array}$ & PAN & $50,1 \%$ & PRI-PVEM-NA \\
\hline Tlaxcala & $\begin{array}{l}\text { Marco Antonio } \\
\text { Mena }\end{array}$ & PRI-PVEM & $33,6 \%$ & PRI-PVEM \\
\hline Veracruz & $\begin{array}{l}\text { Miguel Ángel } \\
\text { Yunes }\end{array}$ & PAN-PRD & $34,4 \%$ & PRI-PVEM-PRV \\
\hline Zacatecas & $\begin{array}{l}\text { Alejandro Tello } \\
\text { Cristerna }\end{array}$ & PRI-PVEM-NA & $37,3 \%$ & PRI-PVEM-NA \\
\hline
\end{tabular}

Fuente: elaboración propia 


\section{PODER EJECUTIVO: CAMBIOS Y DECISIONES CONTROVERSIALES DEL GABINETE}

La figura y la institución presidencial se vieron seriamente impactadas por la combinación de bajísimos niveles de aprobación del Presidente (ver la sección sobre Evaluación de la democracia) y sobre todo, por los escándalos de corrupción y de abuso de poder que han perseguido a Peña Nieto desde el inicio de su sexenio. Sin embargo, y a pesar de la terrible óptica de estos actos, continuaron los gastos superfluos tales como la compra de un nuevo avión presidencial (Boeing 787-8 por un monto mayor a los siete mil millones de pesos) para festejar el 101 aniversario de la Fuerza Aérea Mexicana, y las sospechas de conflictos de interés luego de nuevas revelaciones sobre propiedades en el extranjero de su esposa Angélica Rivera, esta vez, un departamento de 2,05 millones de dólares en Key Biscayne, Florida (Forbes 2016, 9 de agosto).

Por tal motivo, la disculpa pública de Peña Nieto por el caso de la "Casa Blanca" y el reconocimiento de la "indignación" de los mexicanos por cómo se manejó el asunto no surtieron efecto. Dichas declaraciones, realizadas en el marco del lanzamiento del Sistema Nacional de Anticorrupción (SNA) y la promulgación del paquete legislativo para tal efecto, fueron recibidas con profunda desconfianza: $54 \%$ de encuestados dijo creer poco o nada en que el SNA pueda reducir los casos de corrupción (Parametría 2016b). A pesar de que en teoría la creación de dicho sistema constituye un avance, el hecho de que los nombramientos para la titularidad de los mandos de los distintos organismos que lo conforman hayan sido poco transparentes y se haya designado exclusivamente a priístas sigue dando pie a dudar del compromiso del gobierno mexicano por lograr un verdadero cambio. ${ }^{7}$

Durante el año, hubo seis cambios mayores en el gabinete. ${ }^{8}$ En febrero, José Narro Robles fue designado Secretario de Salud, reemplazando a Mercedes Juan López. En julio, Virgilio Andrade renunció a la Secretaría de la Función Pública (SFP) y Javier Vargas quedó como encargado de despacho. En septiembre ocurrieron cuatro de esos cambios, en buena parte debido a la virulenta reacción social y política en contra del Presidente por la invitación de Trump a México. El autor intelectual de la polémica visita, Luis Videgaray, dimitió como Secretario de Hacienda y Crédito Público (SHCP), alegando más tarde que su presencia entorpecería el buen paso por el Congreso de un paquete presupuestario complicado y esencial para el país. Videgaray fue substituido por José Antonio Meade Kuribreña que, a su vez, dejó la SEDESOL. Al mismo tiempo, se sumaron las renuncias de sus dos hombres más cercanos, el titular del Servicio de Administración Tributaria (SAT), Aristóteles Núñez, y de su subsecretario (Fernando Aportela). La Secretaría de Desarrollo Social (SEDESOL) pasó de las

Arely Gómez como titular de la SFP, Raúl Cervantes de la PGR y Chaurand Arzate al Tribunal Federal de Justicia Administrativa (TFJA) (Hernández 2017, 4 de enero).

De un total de 22 realizados hasta septiembre de 2016, de los cuales la mayoría fueron en el rango de subsecretarías (ver Páez 2016). 
manos de Meade a las de Luis Enrique Miranda Nava. Además, la Procuraduría General de la República (PGR) recibió a Raúl Cervantes a cambio de Arely Gómez, que se fue a la SFP.

Finalmente, y si bien no se trató de un cambio en el gabinete, el anuncio el 1 de diciembre de la renuncia de Agustín Carstens al cargo de gobernador de Banxico tras siete años de gestión, para dirigir el Banco de Pagos Internacionales en Suiza, tomó por sorpresa a los mercados nacional e internacional e incrementó las dudas sobre la capacidad de la economía mexicana para hacerle frente al complejo futuro económico inmediato. Aunque la decisión se dice fundamentada en intereses profesionales que no en desacuerdos con Los Pinos, el timing contribuyó a generar mayor incertidumbre y obliga al Ejecutivo a identificar y designar un substituto que esté a la altura de la coyuntura económica actual.

\section{PODER LEGISLATIVO}

El año 2016 marcó la finalización del primer año de la LXIII legislatura, que destaca por presentar una fragmentación partidista sin precedentes en la historia del país. De concentrar más del $90 \%$ de los asientos legislativos en tres partidos hace seis años (Palma 2010), el sistema partidario se ha fragmentado gradualmente, como es descrito con detalle en Freidenberg y Aparicio (2016). Como indica la Figura 3, el número efectivo de partidos en la cámara baja, que es una medida utilizada para medir su número y tamaño relativo, es cercana a cuatro partidos de tamaño similar. Esta cifra es la más alta registrada en los últimos 90 años y muestra tanto la creciente competitividad electoral como la fragmentación de las fuerzas políticas. El incremento sustancial en el número efectivo de partidos sugiere un mayor número de actores políticos y mayor dificultad para modificar el statu quo. 
Gráfico 3. Número efectivo de partidos

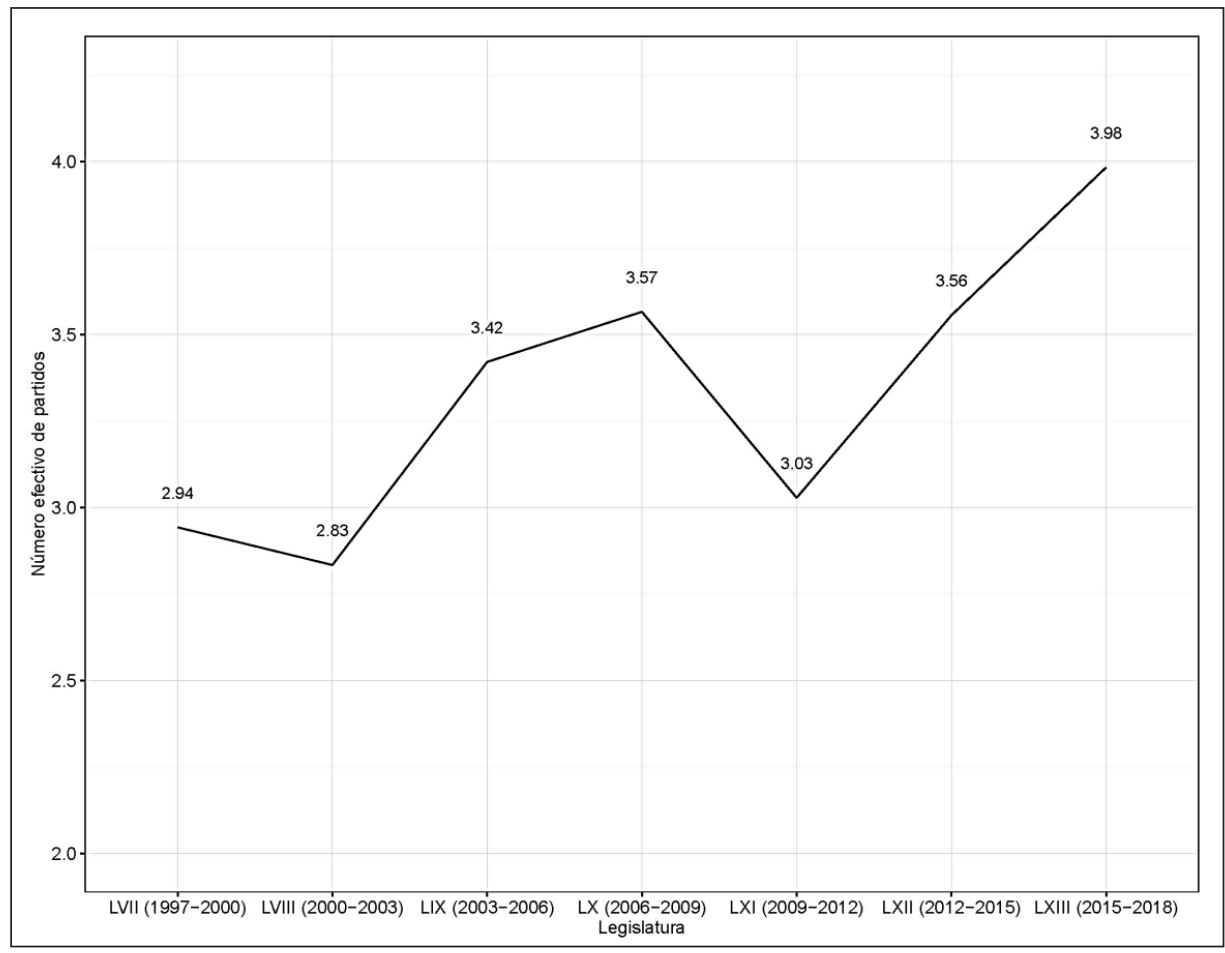

Fuente: Datos recopilados por los autores con información de la Cámara de Diputados. http://www.diputados. gob.mx

Otro hecho histórico es la productividad legislativa en el primer tercio de la legislatura, lo que sugiere la gradual relevancia del congreso como actor fundamental en la elaboración de políticas en el país. De septiembre 2016 a septiembre 2017, fueron presentadas 1.674 iniciativas a la legislatura, un incremento del $45 \%$ comparado con el primer año de la anterior legislatura (2012-2015) y once veces más la productividad registrada en 1997. Sin embargo, la productividad en iniciativas no se ha podido reflejar en el número de leyes aprobadas, ya que solo el $4 \%$ obtuvieron una mayoría legislativa en el pleno. Un caso similar se presentó en el Senado, donde solamente 18 de las 632 iniciativas presentadas fueron aprobadas en el mismo período (Integralia 2016).

Una de las votaciones más relevantes en este año fue la promulgación de la Ley General del Sistema Nacional Anticorrupción, que fue formulada en respuesta a los escándalos de corrupción del Ejecutivo federal (ver sección sobre coyuntura política). Una de las exigencias más sonoras durante su discusión fue la llamada ley "3 de 3 ", que requiere a los representantes públicos de los tres niveles presentar declaraciones patrimonial, de intereses y fiscal. La iniciativa juntó más de 600 mil firmas de ciudadanos así como el apoyo de la opinión pública y la iniciativa privada. 
Sin embargo, esta ley no fue recibida con beneplácito por los diputados. El inciso que incluía la ley " 3 de 3" fue desechada con una votación de 59 votos en contra por 51 a favor, destacando el hecho de que 17 senadores no se presentaron a la votación. Si bien la ley aprobada obligaba a los representantes públicos a presentar sus declaraciones, estas se establecieron como confidenciales y no podían ser públicas. Además, una enmienda adicional definía como sujetos obligados para presentar las declaraciones a cualquier persona física o moral que reciba o ejerza recursos públicos. La ley fue aprobada sin cambios por la Cámara de Diputados un día después.

La ley resultante provocó la frustración del sector civil, que se movilizó para presionar al Presidente para ejercer su derecho constitucional de devolver la ley al Senado para su revisión. Atendiendo la demanda de la opinión pública, Peña Nieto vetó la iniciativa el 27 de junio, solicitando modificaciones en el inciso pertinente. En sesión extraordinaria el 6 de julio, el Senado discutió las revisiones a la ley y eliminó la obligación de particulares a presentar su declaración. Sin embargo, no modificó las restricciones al acceso público de las declaraciones presentadas por los sujetos obligados. La ley fue finalmente promulgada el 18 de julio.

\section{RELACIÓN ENTRE LOS PODERES DEL ESTADO}

Uno de los cambios institucionales más relevantes del año fue la creación de la Ciudad de México (CDMX) como entidad federativa, en sustitución del Distrito Federal. Tras la promulgación de la reforma política en enero, se dio inicio a la tarea de integrar una Asamblea Constitutiva de 100 legisladores, con 60 de ellos elegidos por voto popular (en una circunscripción única, de una lista plurinominal y bajo la regla de representación proporcional) y los 40 restantes por designación de senadores, diputados, del Presidente de la República y del Jefe de Gobierno de la Ciudad..$^{9}$ A pesar de las severas críticas por no ser un órgano plenamente ciudadano y por dejar un coto de poder enorme a políticos en funciones, el Constituyente se instaló oficialmente el 15 de septiembre y comenzó sus labores en el proyecto de constitución que había sido redactado por un grupo de expertos y habían recibido del Jefe de Gobierno, Miguel Ángel Mancera.

En un mes se instalaron ocho comisiones para llevar al cabo los dictámenes de 76 artículos y transitorios, así como de 1.500 iniciativas ciudadanas. Dos fueron los mayores problemas con los que se enfrentó esta Asamblea: primero, el ausentismo, principalmente de los legisladores designados por los políticos. Y segundo, el apremio del tiempo. La Constitución de la Ciudad tendría que 
aprobarse, por decreto presidencial, a más tardar el 31 de enero de 2017. El resultado final fue muy mal recibido por académicos y expertos constitucionales por considerarlo "ilegítimo", al haber sido publicada en la Gaceta Oficial de la Ciudad de México sin previo refrendo popular; y por tratarse de un texto desordenado, lleno más de retórica insulsa y de buenos deseos que de preceptos legales (Silva-Herzog 2017).

En 2016, las manifestaciones multitudinarias del movimiento magisterial y los enfrentamientos con las autoridades siguieron con toda fuerza. Por ejemplo, en Nochixtlán, Oaxaca, policías estatales y federales chocaron con maestros y simpatizantes del CNTE que bloqueaban la autopista Oaxaca-Puebla, dejando un saldo de ocho muertos y, en consecuencia, más bloqueos a vías, manifestaciones, tomas de oficinas y de comercios.

Asimismo, la Suprema Corte de Justicia validó en agosto el artículo 212 de la Ley de Movilidad de la Ciudad de México, según la cual aquellas personas que deseen realizar una manifestación, desfiles, peregrinaciones, caravanas o cualquier otra concentración humana deben dar aviso por escrito por lo menos con 48 horas de anticipación a la Secretaria de Seguridad Pública.

\section{EVALUACIÓN GENERAL SOBRE EL FUNCIONAMIENTO Y CALIDAD DE LA DEMOCRACIA}

El panorama poco alentador para el país ha provocado un ambiente negativo entre la sociedad de cara tanto al gobierno como a la democracia. La clara evidencia de ello es la frecuentemente mencionada baja aprobación presidencial de Enrique Peña Nieto. Como muestra el Gráfico 4, Peña Nieto contaba con niveles de aprobación por debajo al 25\% en la segunda mitad de 2016, una cifra récord en el país desde que se tiene registro. Esta desaprobación es una muestra de la atribución de la opinión pública al bajo crecimiento económico, los escándalos de corrupción y los niveles de violencia en el país.

Dicha caída confirma estudios recientes que exploran la relación entre atribución de responsabilidades al Presidente y su aprobación en general (Carlin, Love y Martínez-Gallardo 2015; Romero, Magaloni y Díaz Cayeros 2016). Una encuesta publicada en el diario Reforma, en enero de 2017, mostró que 78\% de los encuestados percibió un deterioro en la situación económica del país durante los últimos doce meses (Becerra 2017); 60\% de ellos atribuía responsabilidad al presidente Peña. Asimismo, la caída en los niveles de aprobación está en línea con recientes análisis sobre los efectos de los escándalos de corrupción en la aprobación presidencial (Rosas y Manzetti 2015). La combinación de tales efectos hace que la aprobación registrada en el país se encuentre entre las más bajas registradas en 2016 en Latinoamérica. 
Gráfico 4. Histórico de aprobación presidencial

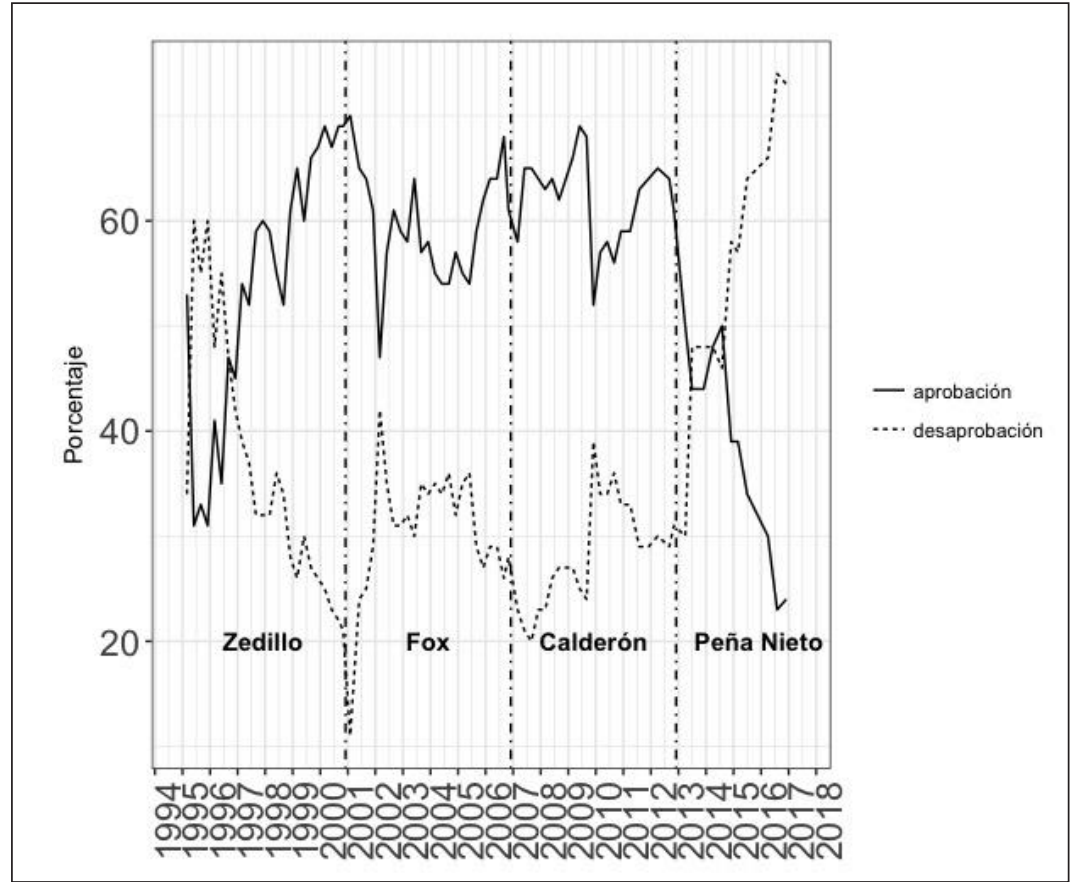

Fuente: Datos recopilados por los autores con datos del periódico Reforma

El desencanto de la población y la nula reacción del gobierno para combatirla han repercutido en las evaluaciones prospectivas de la ciudadanía sobre las condiciones del país y su apoyo a la democracia. La última ola del Latinobarómetro muestra que solo el $48 \%$ de los encuestados en el país está de acuerdo con que la democracia es preferible a cualquier otra forma de gobierno. Esta cifra representa una caída de quince puntos respecto de su reporte más alto registrado en 2002 (63\%). Al mismo tiempo, solamente el 50\% de los encuestados cree que la democracia permite que se solucionen los problemas. Esta cifra está por debajo de la media registrada en Latinoamérica (61\%) y solo supera a la registrada en Chile (47\%).

Considerando la situación descrita en este artículo, no sorprende que el 85\% de la población considere que el país se encuentra en el camino equivocado. Esta cifra se encuentra por arriba de la media internacional (62\%) y solamente por debajo de la tasa a la misma respuesta registrada en Francia (88\%) (Ipsos-MORI 2016).

\section{CONCLUSIÓN}

Es difícil concluir que el cúmulo de eventos negativos en el país durante 2016 sea una excepción o, más bien, parte de una tendencia que irá creciendo con el 
tiempo. Con algunas excepciones, los acontecimientos de este año son similares a los observados en hace una década: la corrupción, el deterioro del poder adquisitivo de la población, y la inseguridad son temas recurrentes en México. Sin embargo, este año ha quedado marcado tanto por la difusión como por la baja tolerancia de la opinión pública a este tipo de eventos. El desencanto con el sistema político y la baja aprobación presidencial no son más que un reflejo del pobre manejo de la situación política y económica de la administración en curso. Podría decirse incluso que la debilidad del Estado Mexicano no está solo en su incapacidad de gestión sino también en su aparente falta de voluntad por siquiera presentarse con una nueva imagen, una estrategia de comunicación o iniciativas de reforma. Más bien pareciera que el gobierno actual se hubiera rendido y que espera solamente a que llegue el fin del sexenio.

La nota positiva frente a este contexto es que al momento en que la opinión pública se vuelve sensible a la situación del país, se incrementan los incentivos para la rendición de cuentas en una democracia. La ley anticorrupción es un ejemplo de la reacción de la clase política ante la presión de la sociedad civil. Sin embargo, poco se puede hacer si la opinión pública solo reacciona ante los escándalos exhibidos por la prensa. El monitoreo continuo de los medios de comunicación y la apertura del debate público debe considerar cuál es el camino institucional, y prevenir o reducir este tipo de experiencias en un futuro no muy lejano.

\section{REFERENCIAS}

ACNUR. 2017, 1 de febrero. "Celebra la inclusión de los derechos humanos de las personas refugiadas en la Constitución de la Ciudad de México." Recuperado el 2 de marzo de 2017 de http:/ /www.acnur.org/noticias/noticia/acnur-celebra-la-inclusion-de-los-derechos-humanos-de-las-personas-refugiadas-en-la-constitucion-de-la-ciudad-de-mexico /

Albarrán, Elizabeth. 2016, 20 de noviembre. "Petróleo aporta 18\% a los ingresos totales". El Economista. Recuperado el 1 de febrero de 2017 de_http://eleconomista.com.mx/finanzas-publicas/2016/11/20/petroleo-aporta-18-ingresos-totales

Aleé, Aarón. 2016, 12 de septiembre. "Fue una mala decisión invitar a Trump: encuesta". El Universal. Recuperado el 25 de febrero de 2017 de http:/ / www.eluniversal.com.mx/articulo/nacion/politica/2016/09/12/fue-una-mala-decision-invitar-trump-encuesta

Amnistía Internacional 2017. Informe anual 2016-17. Londres: Amnistía Internacional. Recuperado el 25 de febrero de 2017 de https:/ /www.amnesty.org/es/countries/americas/ mexico/report-mexico/

Aristegui Noticias. 2016, 5 de agosto. "Cuando Peña decía que Duarte y Borge eran 'el nuevo PRI' (Video)." Recuperado el 26 de mayo de 2017 de http://aristeguinoticias. com/0508/mexico/cuando-pena-decia-que-duarte-era-el-nuevo-pri-video/

Barrientos del Monte, Fernando y Daniel Añorve Añorve. 2014. “México 2013: acuerdos, reformas y descontento." Revista de Ciencia Política 31(1): 221-247.

Beauregard, Luis Pablo. 2016, 15 de junio. "La ultraderecha salta a la política mexicana." El País Digital. Recuperado el 2 de febrero de 2017 de http:/ /internacional.elpais.com/ internacional/2016/06/14/mexico/1465923637_615049.html

Becerra, Lorena. 2017, 18 de enero. “Da ventaja a MORENA desaprobación de EPN.” Reforma. Recuperado el 15 de septiembre de 2017 de http:/ /gruporeforma.reforma.com/interactivo/encuestas/enc_13a_epn/ 
Benton, Allyson Lucinda y Heidi Jane M. Smith. 2017. “The Impact of Parties and Elections on Municipal Debt Policy in Mexico." Governance 30(4): 621-639.

Business Insider. 2016, 23 de noviembre. "The Number of Killings May Fluctuate, but a Brutal Trend is Emerging in Mexico." Recuperado de http:/ / www.businessinsider.com/ mexico-homicides-deadly-violence-trend-2016-2016-11

Carlin, Ryan, Gregory Love y Cecilia Martínez-Gallardo. 2015. “Security, Clarity of Responsibility, and Presidential Approval". Comparative Political Studies 48(8): 438-463.

Casanova, Argentina. 2017, 6 de marzo. "La violencia de género, la guerra contra las mujeres." Animal Político. Recuperado el 3 de junio de 2017 de http:/ / www.animalpolitico.com/ blogueros-seguridad-180/2017/03/06/la-violenciagenero-la-guerra-las-mujeres /

Chávez, VÍctor. 2016, 22 abril. "Filtran lista nominal de electores en Amazon; INE interpone denuncia." El Financiero. Recuperado el 25 de febrero de 2017 de http://www.elfinanciero.com.mx/nacional/lista-nominal-de-electores-disponible-en-amazon-ine-interpone-denuncia.html

CNDH. 2016, 18 de agosto. "Recomendación N 4VG/2016." Recuperado de http://www. cndh.org.mx/sites/all/doc/Recomendaciones/ViolacionesGraves/RecVG_004.pdf

Consulta Mitofsky. 2017. "Se van 12 gobernadores; su aprobación." Recuperado el 2 de febrero de 2017 de http:/ / consulta.mx/index.php/estudios-e-investigaciones/evaluacion-de-gobierno/item/851-se-van-12-gobernadores-sus-aprobaciones

Corporación Latinobarómetro. (2016). Informe Latinobarómetro 2016. Santiago de Chile: Corporación Latinobarómetro. Recuperado de http:/ /www.latinobarometro.org/latNewsShowMore.jsp?evYEAR=2016\&evMONH=9

David, Jimena, Jonathan Furszyfer y Jesús Gallegos. 2017, 16 de marzo. “Pruebas sobre subregistro delictivo." Animal Político. Recuperado el 26 de mayo de 2017 de http:/ / www. animalpolitico.com/blogueros-el-blog-de-mexico-evalua/2017/03/16/victima-cuenta-pruebas-subregistro-delictivo/

El Economista. 2017, 12 de enero. "EPN la gallina de los huevos de oro se acabó, Cantarell se secó." Recuperado el 1 de febrero de 2017 de http://eleconomista.com.mx/socie$\mathrm{dad} / 2017 / 01 / 12 /$ pena-nieto-llama-mantener-apoyos-familias

El Financiero. 2016, 1 diciembre. "Agustin Carstens renuncia al Banco de Mexico." Recuperado el 25 de febrero de 2017 de http://www.elfinanciero.com.mx/economia/carstens-renuncia-al-banco-de-mexico.html

El Universal. 2016, 5 de junio. "Repunta la violencia en víspera de elecciones." Recuperado el 9 de febrero de 2017 de http://www.eluniversal.com.mx/articulo/estados/2016/06/5/repunta-la-violencia-en-vispera-de-la-jornada-electoral

Espinoza, Alejandra. 2015. "10 Razones de la caída del peso frente al dólar. Recuperado el 1 de febrero de 2017 de http://mundoejecutivo.com.mx/economia-negocios/2015/07/30/10-razones-caida-peso-ante-dolar

FEADLE. 2016. "Informe Estadístico de la Fiscalía Especial para la Atención de Delitos Cometidos Contra la Libertad de Expresión, agosto 2016." Recuperado de https:/ / www. scribd.com/document/329780321/Estadisticas-Ago-2016-Totales-1\#

Forbes. 2016, 9 de agosto. "Le encuentran otra 'Casa Blanca' a Angélica Rivera en Miami." Recuperado el 1 de marzo de 2017 de https://www.forbes.com.mx/le-encuentran-otra-casa-blanca-angelica-rivera-miami/\#gs.qm6eF0o

Fox News. 2016, 4 de febrero. “Chapo Guzmán May be in Jail but Mexican Presi. Peña Nieto's Reputation Still Ailing." Recuperado el 25 de mayo de 2017 de http:/ / www.foxnews. com/world/2016/02/04/chapo-guzman-may-be-in-jail-but-mexican-pres-pena-nieto-reputation-still-ailing.html

Freidenberg, Flavia y Francisco Javier Aparicio. 2016. “México 2015: entre la fragmentación partidista y el descontento ciudadano." Revista de Ciencia Política, 36(1): 219-238.

García, Jacobo. 2017, 12 de abril. "La corrupción de los gobernadores sacude México y cerca a Peña Nieto." El País. Recuperado el 26 de mayo de 2017 de http://internacional. elpais.com/internacional/2017/04/11/mexico/1491939865_555849.html 
GIEI. 2016, 3 de marzo. "Presentación del GIEI, del Informa sobre el caso de los 43 desaparecidos de Ayotzinapa en México." Recuperado de http:/ / media.wix.com/ugd/3a9f6f_ 49879d0ce59f4d959dc5d86c0890a739.pdf

Heras, Antonio. 2016, 26 de octubre. "Flujo de haitianos y africanos no se resolverá en breve: Osorio Chong." La Jornada Baja California. Recuperado el 1 de marzo de 2017 de http:/ /jornadabc.mx/tijuana/26-10-2016/flujo-de-haitianos-y-africanos-no -se-resolvera-en-breve-osorio-chong

Hernández, Leopoldo. 2017, 4 de enero. "Critican elección de otro priista para SNA." El Economista. Recuperado de http://eleconomista.com.mx/sociedad/2017/01/04/critican-eleccion-otro-priista-sna

Hernández, Leopoldo. 2017, 10 de febrero. "Alerta ACNUR de incremento de solicitudes como refugiados." El Economista. Recuperado el 10 de febrero de 2017 de http:// eleconomista.com.mx/sociedad/2017/02/10/alerta-acnur-incrementosolicitudes-como-refugiados

Ipsos-Mori. 2016. "What Worries The World." Recuperado el 4 de agosto de 2017 de https:// www.ipsos.com/sites/default/files/2016-12/What_Worries_the_World_Oct_2016.pdf

INE. 2016, 20 de diciembre. "Reforzará INE medidas de seguridad de acceso y manejo de datos personales al Padrón Electoral y Lista Nominal", recuperado el 1 de marzo de 2017 de http://www.ine.mx/archivos3/portal/historico/contenido/comunicados/2016/12/20161220.html

INEGI. 2016. “Encuesta Nacional de Acceso a la Información Pública y Protección de Datos Personales 2016." Recuperado el 4 de junio de 2017 de http:/ /www3.inegi.org.mx/ $\mathrm{rnm} /$ index.php/catalog/223

Instituto Nacional de las Mujeres. 2017. "Alerta de Violencia de Género contra las Mujeres." Recuperado de https://www.gob.mx/inmujeres/acciones-y-programas/alerta-de-violencia-de-genero-contra-las-mujeres-80739

Instituto para la Economía y la Paz (IPE). "Índice de paz México 2017." Recuperado el 26 de mayo de 2017 de http://visionofhumanity.org/app/uploads/2017/04/MPI17_Spanish_Report_WEB_28.03.pdf

Integralia. 2016. Reporte Legislativo. Número siete (septiembre 2015-agosto 2016). Ciudad de México: Integralia.

Langston, Joy y Bernardo Pérez. 2009. "México 2008: El año en que se vivió en peligro." Revista de Ciencia Política 29(2): 491-513.

Lozano, Sergio y Alfredo González. 2017, 2 de febrero. "Igualan remesas a programa social." Reforma, Negocios, 1.

Magar, Eric y Vidal Romero. 2008. "México: Reformas pese a un gobierno dividido." Revista de Ciencia Política 28(1): 265-285.

México Evalúa. 2017. “Cada Víctima Cuenta." Recuperado el 26 de mayo de 2017 de http:/ / mexicoevalua.org/2017/03/07/cada-victima-cuenta-hacia-un-sistema-de-informacion-delictiva-confiable/

OEA. 2016, 27 de septiembre. "CIDH envía caso sobre México a la Corte IDH." Recuperado el 25 de febrero de 2017 de http: / / www.oas.org/es/cidh/prensa/comunicados/2016/140.asp

OECD. 2016 "Income Inequality Remains High in the Face of Weak Recovery." Recuperado el 1 de marzo de 2017 de http:/ / www.oecd.org/social/OECD2016-Income-Inequality-Update.pdf

Olmeda, Juan y María Alejandra Armesto. 2013. "México: El regreso del PRI a la Presidencia." Revista de Ciencia Política 33(1): 247-267.

Páez, Erik. 2016, 16 de septiembre. "22 movimientos en el gabinete de Peña Nieto." El Economista. Recuperado de http://eleconomista.com.mx/politica/2016/09/16/22-movimientos-gabinete-pena-nieto

Palma, Esperanza. 2010. "México: Entre la violencia y la consolidación del sistema de partidos." Revista de Ciencia Política 30(1): 379-396. 
Parametría. 2016a. "Aventaja PAN rumbo a la elección presidencial." Recuperado el 2 de febrero de 2016 de www.parametria.com.mx\%2FdescargarCarta.php\%3Fid\%3DAventaja_PAN_rubo_a_la_eleccion_presidencial.pdf

Parametría. 2016b. "Más mexicanos desconocen el Sistema Nacional Anticorrupción." Recuperado el 3 de marzo de 2017 de http: / / www.parametria.com.mx/carta_parametrica. php?cp $=4897$

Puig, Carlos. 2017, 19 de abril. “Javidú, ese príista." Milenio. Recuperado el 26 de mayo de 2017 de http://www.milenio.com/firmas/carlos_puig/javier_duarte-amlo-desvio-dinero-investigacion-miguel_angel_yunes_18_941485888.html

Rebolledo, Ruy Alonso. 2016, 29 de agosto. "Demandan aprobación de ley de desaparecidos." El Economista. Recuperado el 25 de febrero de http://eleconomista.com.mx/sociedad/2016/08/29/demandan-aprobacion-ley-desaparecidos

Reporteros Sin Fronteras. 2017. “Informe Anual: México 2016." Recuperado el 3 de marzo de 2017 de http:/ / www.informeanualrsf.es/news/mexico2/

Romero, Vidal, Beatriz Magaloni y Alberto Díaz-Cayeros. 2016. "Presidential Approval and Public Security in Mexico's War on Crime." Latin American Politics and Society 58(2): 100-123.

Rosas, Guillermo y Luigi Manzetti. 2015. "Reassessing the Trade-off Hypothesis: How Misery Drives the Corruption Effect on Presidential Approval." Electoral Studies 39: 26-38.

Silva-Herzog, Jesús. 2017, 6 de febrero. "La Constitución de la Ciudad." El Siglo de Torreón. Recuperado el 1 de marzo de 2017 de http:/ / hemeroteca.elsiglodetorreon.com.mx/ pdf/dia/2017/02/06/06tora07.pdf?i\&acceso=21f6092039d4357c1e11e3cbd72bd3f3

Temkin Yedwad, Benjamín y Rodrigo Salazar-Elena. 2012. "México 2010-2011. Los últimos años de una gestión cuestionada." Revista de Ciencia Política 32(1): 193-210.

The Economist. 2016, 1 de septiembre. "The Unspeakable and the Inexplicable." Recuperado el 25 de febrero de 2017 de http://www.economist.com/news/americas / 21706345-why-did-enrique-pe-nieto-invite-donald-trump-visit-mexico-unspeakable-and?fsrc=scn/tw_ec/the_unspeakable_and_the_inexplicable

The Economist. 2017, 5 de enero. "Remittances to Mexico Spike in Anticipation to Donald Trump's Wall". Recuperado el 11 de enero de 2017 de http:/ /www.economist.com/ node/21713833/print

Transparency International. 2017, 25 de enero. “Corruption Perceptions Index 2016." Recuperado el 25 de mayo de 2017 de https:/ / www.transparency.org/news/feature/corruption_perceptions_index_2016

Valdez, Javier. 2016, 22 de septiembre. “Grupo de hermano de 'El Chapo' 'toma' comunidades de Sinaloa.” La Jornada. Recuperado el 3 de marzo de 2017 de http: / /www.jornada. unam.mx/ultimas/2016/09/22/grupo-armado-de-hermano-de-el-chapo-toma-comunidad-de-badiraguato

Francisco Cantú es profesor asistente de Ciencia Política en la Universidad de Houston (Estados Unidos). Correo electrónico: fcantu10@uh.edu

Verónica Hoyo es investigadora asociada en el Centro de Estudios Comparados sobre Inmigración (CCIS) en la Universidad de California, San Diego (Estados Unidos). Correo electrónico: vhoyo@ ucsd.edu 
- 